\title{
Análise de crescimento do capim Coastcross-1 sob adubação nitrogenada em duas idades de rebrotação ${ }^{1}$
}

\section{Odilon Gomes Pereira2 ${ }^{2}$ Marco Antônio de Oliveira ${ }^{3}$, José Cardoso Pinto ${ }^{4}$, Manoel Eduardo Rozalino Santos ${ }^{5}$, Karina Guimarães Ribeiro ${ }^{6}$, Paulo Roberto Cecon ${ }^{7}$}

\author{
1 Pesquisa financiada pela FAPEMIG. \\ 2 Departamento de Zootecnia da Universidade Federal de Viçosa. \\ 3 Programa de Pós-graduação em Zootecnia da Universidade Federal de Viçosa \\ ${ }^{4}$ Departamento de Zootecnia da Universidade Federal de Lavras. \\ 5 Faculdade de Medicina Veterinária da Universidade Federal de Uberlândia. \\ ${ }^{6}$ Departamento de Zootecnia da Universidade Federal dos Vale do Jequitinhonha e Mucuri. \\ ${ }^{7}$ Departamento de Informática da Universidade Federal de Viçosa.
}

RESUMO - Avaliaram-se os índices de crescimento do capim Coastcross-1 sob cinco doses de nitrogênio (0, 100, 200, 300 e $400 \mathrm{~kg} / \mathrm{ha}$.ano) e duas idades de rebrotação (28 e 42 dias). As doses de nitrogênio foram arranjadas em esquema fatorial $5 \times 2$, em blocos ao acaso, com três repetições. A adubação nitrogenada foi parcelada em três aplicações, realizadas logo após os cortes. Maiores valores de relação folha/colmo e razão de peso foliar foram obtidos aos 28 dias, em comparação aos 42 dias de rebrotação. Houve redução linear na relação folha/colmo com a adubação nitrogenada (de 1,6 para 1,0 nas doses de 0 e $133 \mathrm{~kg} / \mathrm{ha}$.corte de N). Por outro lado, a adubação nitrogenada aumentou linearmente a área foliar específica do capim Coastcross-1 aos 28 dias de rebrotação (de 10,3 a 20,8 m²/kg com o incremento de 0 a $133 \mathrm{~kg} / \mathrm{ha}$.corte de N), resultando em elevação da sua razão de área foliar. Na ausência de nitrogênio, a área foliar específica foi maior aos $42 \mathrm{dias}(14,3 \mathrm{~m} / \mathrm{kg}) \mathrm{em}$ relação aos 28 dias de rebrotação $\left(8,6 \mathrm{~m}^{2} / \mathrm{kg}\right)$. A idade de rebrotação e a adubação nitrogenada modificam o padrão de acúmulo de forragem e as características do pasto de capim Coastcross-1. Durante a estação de maior crescimento, o pasto de capim Coastcross-1 adubado com maior dose de nitrogênio deve ser manejado com menor idade de rebrotação (28 dias).

Palavras-chave: adubação, Cynodon dactylon, índice de área foliar, relação folha/colmo

\section{Growth analysis of Coastcross-1 bermudagrass grown under nitrogen doses at two regrowth ages}

\begin{abstract}
The Coastcross-1 growth index in relation to five nitrogen doses (0, 100, 200, 300 and $400 \mathrm{~kg} / \mathrm{ha} . y e a r)$ and two regrowth ages (28 and 42 days) were evaluated. Nitrogen doses were arranged in a $5 \times 2$ factorial scheme in a randomized complete block design with three repetitions. Nitrogen fertilization was performed in three applications right after the forage harvesting. Higher values for leaf/stem and leaf weight ratio were observed at 28-d regrowth, in comparison with the 42 days of regrowth. Linear reduction of leaf/stem ratio from 1.6 to 1.0 at 0 and $133 \mathrm{~kg} \mathrm{~N} / \mathrm{ha}$.harvest, respectively was observed. The specific leaf area of bermudagrass at 28-d regrowth resulted in increased leaf area ratio (from 10.3 to $20.8 \mathrm{~m}^{2} / \mathrm{kg}$ with the increase of 0 to $133 \mathrm{~kg} \mathrm{~N} / \mathrm{ha}$. Harvest). At the absence of $\mathrm{N}$ treatment, specific leaf rate was higher at $42-\mathrm{d}\left(14.3 \mathrm{~m}^{2} / \mathrm{kg}\right) \mathrm{in} \mathrm{relation}$ to the 28-d of regrowth $\left(8.6 \mathrm{~m}^{2} / \mathrm{kg}\right)$. Regrowth age and nitrogen fertilization modify the pattern of forage accumulation and the characteristics of Coastcross-1 pasture. During the summer, the Coastcross- 1 grass pasture fertilized with the highest $\mathrm{N}$-dose should be managed at a younger regrowth age (28-d).
\end{abstract}

Key Words: Cynodon dactylon, fertilization, leaf area index, leaf/stem ratio

\section{Introdução}

O capim Coastcross-1 é um híbrido estéril oriundo do cruzamento do cultivar Coastal (C. dactylon) com uma introdução proveniente do Quênia (C. nlemfuensis var. robustus). Foi liberado para plantio em 1967 e introduzido na década de 70 no Brasil, onde tem apresentado boa produtividade primária e secundária (Vilela et al., 2005).

Dessa forma, experimentos com o capim Coastcross1 sob regime de cortes são importantes para conhecer sua morfologia e fisiologia, bem como otimizar sua utilização sob distintas condições ambientais. Para esse fim, a análise de crescimento é adequada, pois permite 
identificar as características da planta determinantes da sua produtividade e associadas à sua adaptação ao ambiente (Lambers, 1987).

Os índices de crescimento podem ser calculados conhecendo-se o peso de matéria seca de toda a planta ou de suas partes e a dimensão da sua área foliar durante certo intervalo de tempo. As principais características de crescimento são: taxa de crescimento da cultura; taxa de crescimento relativo; taxa assimilatória líquida; razão de área foliar, que se decompõe em área foliar específica e razão de peso foliar; índice de área foliar e duração de área foliar (Radford, 1967). A razão de peso foliar corresponde à fração da matéria seca não exportada das folhas para as outras partes da planta (Benincasa, 1988). Já a área foliar específica é a relação entre a área foliar e o peso de matéria seca de folhas, sendo seu inverso a espessura da folha (Benincasa, 1988). Por outro lado, o índice de área foliar representa a área de folha por unidade de área de solo (Watson, 1952), indicando a capacidade de interceptação da luz pela planta.

As características de crescimento são influenciadas pelo nitrogênio, que estimula a taxa de alongamento e aparecimento foliar (Rovetta, 2000; Fagundes et al., 2006) e incrementa a área foliar do perfilho, contribuindo para o maior peso da lâmina foliar. Contudo, o padrão de desenvolvimento da forrageira adubada com nitrogênio também é afetado por ações de manejo da desfolhação, tal como a idade da planta no momento do corte (Oliveira et al., 2000; Rovetta, 2000). Dessa forma, é possível que existam interações entre os fatores dose de nitrogênio e idade de rebrotação da forrageira sobre seus índices de crescimento.

Portanto, com o intuito de compreender melhor os processos determinantes da produção de forragem e auxiliar o manejo, foram avaliados os índices de crescimento do capim Coastcross-1 na Zona da Mata Mineira sob cinco doses de nitrogênio e duas idades de rebrotação.

\section{Material e Métodos}

O experimento foi realizado no período de novembro de 1999 a março de 2000 em pasto de capim-coastcross (Cynodon dactylon (L.) Pers.) pertencente ao Departamento de Zootecnia da Universidade Federal de Viçosa, em Viçosa, MG (2045' S; 4251' W; 651 m). A análise química do solo, classificado como podzólico vermelho-amarelo de textura franco argilo-arenosa, foi realizada no início do período experimental, na camada $0-20 \mathrm{~cm}$ de profundidade, e apresentou os seguintes resultados: $\mathrm{pH}$ em $\mathrm{H}_{2} \mathrm{O}: 7,04 ; \mathrm{P}: 2,2$ (Mehlich-1) e K: $189 \mathrm{mg} / \mathrm{dm}^{3} ; \mathrm{Ca}^{2+}: 1,5 ; \mathrm{Mg}^{2+}: 0,5 \mathrm{e} \mathrm{Al}^{3+}$ : $0,2 \mathrm{cmol}_{\mathrm{c}} / \mathrm{dm}^{3}(\mathrm{KCl} 1 \mathrm{~mol} / \mathrm{L})$.

Com base nos resultados da análise química do solo, a calagem foi realizada superficialmente a fim de elevar a saturação por bases para $60 \%$, com a aplicação de calcário dolomítico (PRNT = 80\%). A aplicação do adubo fosfatado, em superfície e na dose de $60 \mathrm{~kg} / \mathrm{ha}$ de $\mathrm{P}_{2} \mathrm{O}_{5}$, foi feita no dia $4 / 11 / 1999$, usando como fonte o superfosfato simples. Nos dois primeiros cortes, foram aplicados $40 \mathrm{~kg} / \mathrm{ha}$ de $\mathrm{K}_{2} \mathrm{O}$, juntamente com a adubação nitrogenada, usando-se como fonte o cloreto de potássio.

A área experimental foi irrigada por sistema de aspersão quando ocorriam períodos de aproximadamente uma semana sem chuvas, objetivando-se evitar os efeitos desfavoráveis do veranico, muito comum na região de Viçosa durante os meses de janeiro e fevereiro, sobre o desenvolvimento da forrageira (Tabela 1).

Foram avaliadas cinco doses de nitrogênio $(0,100,200$, 300 e $400 \mathrm{~kg} / \mathrm{ha}$.ano de N) e duas idades de rebrotação (28 e 42 dias), em ensaio fatorial $(5 \times 2)$, arranjado no delineamento em blocos casualizados, com três repetições. Dessa forma, a área experimental foi constituída de 30 parcelas (unidades experimentais), cada uma medindo $6 \mathrm{~m}^{2}$ $(2 \mathrm{~m} \times 3 \mathrm{~m})$.

As doses do fertilizante nitrogenado, na forma de sulfato de amônio, foram divididas em três aplicações durante o período experimental. Desse modo e de acordo com o tratamento, cada parcela recebeu $1 / 3$ da dose de nitrogênio preconizada (0, 33, 66, 100 ou 133 kg/ha de N) por aplicação. A primeira aplicação do adubo nitrogenado ocorreu após o corte de uniformização (04/11/1999), enquanto que a segunda e terceira foram feitas após o $1^{0}$ e o $2^{0}$ corte nas duas idades de rebrotação (28 e 42 dias) (Tabela 2).

Tabela 1 - Totais mensais de precipitação pluvial e médias mensais de temperatura máxima, temperatura mínima, temperatura média e umidade relativa do ar durante o período de novembro de 1999 a março de 2000

\begin{tabular}{|c|c|c|c|c|c|}
\hline Mês/Ano & $\begin{array}{l}\text { Precipitação } \\
\text { pluvial (mm) }\end{array}$ & $\begin{array}{l}\text { Temperatura } \\
\text { máxima }\left({ }^{\circ} \mathrm{C}\right)\end{array}$ & $\begin{array}{l}\text { Temperatura } \\
\text { mínima }\left({ }^{\circ} \mathrm{C}\right)\end{array}$ & $\begin{array}{l}\text { Temperatura } \\
\text { média }\left({ }^{\circ} \mathrm{C}\right)\end{array}$ & $\begin{array}{l}\text { Umidade } \\
\text { relativa (\%) }\end{array}$ \\
\hline Novembro/1999 & 375,3 & 25,5 & 16,2 & 20,0 & 78,7 \\
\hline Dezembro/1999 & 108,9 & 27,7 & 18,7 & 22,4 & 81,1 \\
\hline Janeiro/2000 & 288,5 & 28,2 & 19,1 & 22,6 & 83,9 \\
\hline Fevereiro/2000 & 148,2 & 28,9 & 18,6 & 22,6 & 82,9 \\
\hline Março/2000 & 105,1 & 27,3 & 18,4 & 21,7 & 86,0 \\
\hline
\end{tabular}


Tabela 2 - Datas dos cortes e alturas ao tempo do corte do capim Coastcross-1 adubado com cinco doses de nitrogênio (N) e colhido aos 28 e 42 dias de rebrotação, durante três cortes sucessivos no período de verão

\begin{tabular}{cccc}
\hline Corte & Data de corte & Idade de rebrotação $($ dia) & Altura $(\mathrm{cm})$ das plantas sob $0,33,66,100$ e 133 kg/ha.corte de N, respectivamente \\
\hline $1 \underline{\underline{o}}$ & $02 / 12 / 99$ & 28 & $15 ; 26 ; 27 ; 34 ; 35$ \\
$2 \underline{\underline{o}}$ & $30 / 12 / 99$ & 28 & $21 ; 41 ; 53 ; 55 ; 54$ \\
$3^{\underline{\underline{o}}}$ & $27 / 01 / 00$ & 28 & $22 ; 45 ; 47 ; 55 ; 56$ \\
$1 \underline{\underline{o}}$ & $16 / 12 / 99$ & 42 & $28 ; 41 ; 55 ; 56 ; 61$ \\
$2^{\underline{o}}$ & $26 / 01 / 00$ & 42 & $38 ; 52 ; 61 ; 63 ; 62$ \\
$3^{\underline{\underline{o}}}$ & $09 / 03 / 00$ & 42 & $39 ; 51 ; 60 ; 64 ; 63$ \\
\hline
\end{tabular}

*O corte de uniformização foi realizado em todas as parcelas no dia 04/11/1999.

Por ocasião dos cortes e em cada parcela, colheu-se a forragem presente em 1,0 $\mathrm{m}^{2}$ de área útil, ao nível de $5 \mathrm{~cm}$ da superfície do solo. O material colhido foi pesado em balança tipo dinamômetro, com divisão de $10 \mathrm{~g}$ e, posteriormente, uma subamostra de cerca de $400 \mathrm{~g}$ foi acondicionada em saco de papel, pesada e colocada para secar em estufa de ventilação forçada a $65^{\circ} \mathrm{C}$. Com isso, foi possível determinar a produção de massa de forragem, expressa em matéria seca, por unidade de área.

De cada amostra, também foi retirada uma segunda subamostra, que foi colocada em saco plástico previamente umedecido e identificado, e levada imediatamente ao laboratório, onde suas frações lâmina foliar e colmo foram separadas. Estas frações, separadamente, foram acondicionadas em sacos de papel e submetidas à secagem em estufa de ventilação forçada a $65{ }^{\circ} \mathrm{C}$, por 72 horas. De posse dos dados de peso da massa seca de lâmina foliar e colmo, determinou-se a relação folha/colmo (RFC) do pasto. Com base nos valores de RFC e de produção de forragem, estimou-se a massa de lâmina foliar (MLF) presente em $1 \mathrm{~m}^{2}$.

As medições de área laminar foram realizadas em aparelho medidor de área (Sistema de Análise de Imagem, Delta - T). Para isso, uma amostra constituída de 30 perfilhos foi colhida em cada parcela, acondicionada em saco plástico identificado e levada para o laboratório, onde teve suas lâminas foliares destacadas e passadas no aparelho medidor de área. Depois, cada amostra de lâmina foliar foi colocada em saco de papel e mantida em estufa de ventilação forçada a $65^{\circ} \mathrm{C}$, por 72 horas, para determinação de sua massa seca. A estimativa da área foliar total (AF) das lâminas foliares verdes presentes na área útil de $1 \mathrm{~m}^{2}$ foi obtida, multiplicando-se o MLF (em $1 \mathrm{~m}^{2}$ ) pela área foliar de 30 perfilhos e dividindo o produto pelo peso da massa seca de lâmina foliar dos 30 perfilhos. O IAF foi então determinado pelo quociente da área foliar pela área de solo (no caso $1 \mathrm{~m}^{2}$ ).

Os índices de crescimento razão de área foliar (RAF), área foliar específica (AFE) e razão de peso foliar (RPF) foram calculados segundo Benincasa (1988), através das seguintes fórmulas:
a) $\mathrm{RAF}=\mathrm{AF} / \mathrm{PMS}$
b) $\mathrm{AFE}=\mathrm{AF} / \mathrm{MLF}$
c) $\mathrm{RPF}=\mathrm{RAF} / \mathrm{AFE}$
em que:

AF = área foliar total (em $\left.1 \mathrm{~m}^{2}\right)$;

PMS = peso da matéria seca total (utilizou-se apenas o peso da matéria seca da parte aérea, sem raízes, colhida em $\left.1 \mathrm{~m}^{2}\right)$; e

MLF = massa de lâmina foliar $\left(\mathrm{em} 1 \mathrm{~m}^{2}\right)$.

A área foliar por perfilho (AFP) foi obtida, dividindo-se a área foliar acumulada e mensurada no aparelho pelo número 30, que correspondeu à quantidade de perfilhos amostrados.

A densidade populacional de perfilhos foi determinada pela colheita de todos os perfilhos contidos no interior de um quadrado de 0,25 m de lado. Esses perfilhos foram acondicionados em sacos plásticos identificados e, em seguida, levados para o laboratório, onde foram quantificados. De posse desses valores, estimou-se o número de perfilhos por $\mathrm{m}^{2}$ em cada parcela, multiplicando-se o número de perfilhos presentes no interior do quadrado de área conhecida $\left(0,0625 \mathrm{~m}^{2}\right)$ por 16 .

As análises dos dados experimentais foram feitas usando o Sistema para Análises Estatísticas - SAEG, versão 5.0 (Euclides, 1993). Os dados de cada variável resposta foram submetidos às análises de variância e de regressão. Para o fator idade, as médias foram comparadas utilizando-se o teste F. Para o fator dose de nitrogênio, ajustaram-se modelos de regressão, que foram escolhidos com base no coeficiente de determinação, na natureza do fenômeno em estudo e na significância dos coeficientes de regressão, testada pelo teste $\mathrm{F}$ e em nível de até $10 \%$ de probabilidade.

\section{Resultados e Discussão}

No primeiro e no segundo corte, os maiores valores de razão de peso foliar (RPF) ocorreram aos 28 dias em comparação aos 42 dias de rebrotação (Tabela 3). Esse mesmo padrão de resposta ocorreu para a relação folha/colmo (RFC) do capim-coastcross em todos os cortes 
Tabela 3 - Valores médios dos índices de crescimento do capim-coastcross, em duas idades de rebrotação e em três cortes sucessivos no verão

\begin{tabular}{|c|c|c|c|c|}
\hline \multirow[t]{2}{*}{ Idade de rebrotação (dia) } & \multicolumn{3}{|c|}{ Corte } & \multirow[b]{2}{*}{ Média } \\
\hline & 1 & 2 & 3 & \\
\hline \multicolumn{5}{|c|}{ Razão de área foliar $\left(\mathrm{m}^{2} / \mathrm{kg}\right)$} \\
\hline 28 & $11,6 \mathrm{a}$ & $8,5 \mathrm{a}$ & $8,5 a$ & 9,5 \\
\hline 42 & $10,7 \mathrm{a}$ & $5,8 b$ & $8,3 \mathrm{a}$ & 8,3 \\
\hline \multicolumn{5}{|c|}{ Área foliar específica $\left(\mathrm{m}^{2} / \mathrm{kg}\right)$} \\
\hline 28 & $19,9 \mathrm{a}$ & $16,3 a$ & $15,6 a$ & 17,3 \\
\hline 42 & $21,0 \mathrm{a}$ & $12,4 \mathrm{~b}$ & $16,5 a$ & 16,6 \\
\hline \multicolumn{5}{|c|}{ Razão de peso foliar (g/g) } \\
\hline 28 & $0,5845 a$ & $0,5263 a$ & $0,5590 \mathrm{a}$ & 0,5566 \\
\hline 42 & $0,5125 b$ & $0,4686 b$ & $0,5043 a$ & 0,4951 \\
\hline \multicolumn{5}{|c|}{ Relação folha/colmo } \\
\hline 28 & $1,42 \mathrm{a}$ & $1,12 \mathrm{a}$ & $1,30 \mathrm{a}$ & 1,28 \\
\hline 42 & $1,06 b$ & $0,88 \mathrm{~b}$ & $1,02 b$ & 0,99 \\
\hline \multicolumn{5}{|c|}{ Índice de área foliar } \\
\hline 28 & $0,84 \mathrm{~b}$ & $2,70 a$ & $2,25 \mathrm{a}$ & 1,93 \\
\hline 42 & $3,66 a$ & $2,79 a$ & $2,77 a$ & 3,07 \\
\hline \multicolumn{5}{|c|}{ Área foliar por perfilho $\left(\mathrm{m}^{2}\right)$} \\
\hline 28 & $0,0022 b$ & $0,0016 \mathrm{~b}$ & $0,0025 b$ & 0,0021 \\
\hline 42 & $0,0031 \mathrm{a}$ & $0,0024 \mathrm{a}$ & $0,0030 \mathrm{a}$ & 0,0028 \\
\hline
\end{tabular}

Médias seguidas de mesma letra na coluna, para cada variável, não diferem pelo teste $\mathrm{F}(\mathrm{P}>0,05)$.

(Tabela 3). O decréscimo na RPF e RFC com a maturidade das plantas tem sido relatado em vários trabalhos com gramíneas tropicais (Oliveira et al., 2000a; Oliveira et al., 2000b; Rovetta, 2000; Gomide et al., 2003).

A redução na RPF do capim Coastcross-1 com o aumento da idade de rebrotação pode ser atribuída à diminuição na sua relação folha/colmo com o tempo (Tabela 3). Durante o desenvolvimento da planta, maior percentual de fotoassimilados passa a ser alocado para a síntese de colmo em detrimento de folhas. O desenvolvimento do colmo garante a sustentação das novas folhas, porque o diâmetro das estruturas de suporte (colmo) altera-se em proporção direta à força requerida para suportar seus órgãos (folhas) (McMahom, 1973).

Além disso, na idade de rebrotação de 42 dias, é provável que o capim Coastcross-1 permaneceu por mais tempo com um índice de área foliar (IAF) superior ao IAF crítico, a partir do qual se inicia a competição por luz no dossel. Nessa condição, acentua-se o processo de alongamento do colmo para expor as novas folhas na região superior do dossel, onde a luminosidade é maior (Lemaire, 2001). Isso também pode ter contribuído para os menores valores de RPF e RFC da forrageira sob maior idade de rebrotação (42 dias).

O índice de área foliar foi influenciado pela idade de rebrotação apenas no primeiro corte, registrando-se maior $(\mathrm{P}<0,05)$ valor em plantas colhidas aos 42 dias do que naquelas sob cortes a cada 28 dias (Tabela 3). Em trabalho com gramíneas do gênero Cynodon, Oliveira et al. (2000a) e Gomide (1996) também observaram que o IAF atingiu valores máximos aos 42 e 47 dias de crescimento, respectivamente. O incremento do IAF até a idade de rebrotação de 42 dias esteve relacionado com a elevação da área foliar por perfilho (AFP) nessa situação de manejo (Tabela 3). Em verdade, nesse trabalho, observou-se correlação $(\mathrm{P}<0,01)$ positiva do IAF com AFP $(r=0,72)$, demonstrando possibilidade de relação de causa e efeito entre essas variáveis.

Outro fato que permite inferir que a AFP foi o principal determinante do IAF do capim Coastcross-1 diz respeito à densidade populacional de perfilho, que não foi influenciada ( $P>0,05)$ pela idade de rebrotação e nem pela adubação nitrogenada, observando-se valores médios de 2.756, 2.957 e 2.529 perfilhos por $\mathrm{m}^{2}$ no primeiro, segundo e terceiro cortes, respectivamente.

Quando o corte foi feito na idade de 42 dias, os perfilhos do capim Coastcross-1 estavam com maior estádio de desenvolvimento e, com efeito, acumularam maior número de fitômeros. Como o fitômero é constituído, dentre outros órgãos, de lâmina foliar (Taiz \& Zeiger, 2006), é natural o incremento da área foliar por perfilho na medida em que os mesmos alcançam maior idade (42 dias), desde que o processo de senescência foliar não se acentue. Em capim-tifton 85, Oliveira et al. (2000) também observaram aumento de 0,0054 para $0,0076 \mathrm{~m}^{2}$ na AFP dos 28 aos 42 dias de rebrotação.

Ficou evidente, então, que variações no manejo da desfolhação, caracterizado nesse trabalho pela frequência 
de cortes, influenciam a área foliar de perfilhos individuais do capim Coastcross-1, o que, provavelmente, é consequência de modificações nas suas características morfogênicas e estruturais (Chapman \& Lemaire, 1993).

Com relação ao segundo corte, verificou-se maior $(\mathrm{P}<0,05)$ valor de razão de área foliar (RAF) aos 28 dias de rebrotação, em comparação à idade de 42 dias (Tabela 3). Vários autores também relataram redução nos valores de RAF com o crescimento das plantas (Benincasa, 1988; Oliveira et al., 2000a). Durante o início do desenvolvimento vegetativo do pasto, há maior aporte de assimilados para a produção de folhas, a fim de aumentar a interceptação da luz e assegurar seu rápido crescimento. Contudo, com o decorrer do tempo, devido ao efeito do maior sombreamento das folhas inferiores pelas folhas superiores (autosombreamento), ocorre maior competição por luz no dossel e aumento da senescência foliar (Lemaire, 2001), o que faz com que a área foliar e, consequentemente, a RAF da forrageira decresça a partir de idades mais avançadas.

A razão de área foliar consiste em característica morfofisiológica que indica a quantidade de área foliar útil para a fotossíntese em relação à massa total da forrageira. Desse modo, o decréscimo da RAF quando o capim Coastcross- 1 foi submetido ao intervalo de corte de 42 dias demonstra que uma mesma unidade da área foliar tem que sintetizar fotoassimilados para sustentar a respiração de uma maior massa seca da forrageira (Benincasa, 1988), o que pode limitar o acúmulo de forragem no pasto.

No segundo corte, a área foliar específica (AFE) também foi menor $(\mathrm{P}<0,05)$ aos 42 dias de rebrotação em comparação à idade de 28 dias (Tabela 3), indicando superior espessura das folhas na condição de cortes a cada 42 dias. Esses resultados estão em concordância com os obtidos por Benincasa (1988), Oliveira et al. (2000a) e Rovetta (2000), e podem ser atribuídos ao maior percentual de tecidos internos, determinado pelo aumento em número e tamanho das células mesofílicas (Benincasa, 1988), o que diminui a AFE e, por outro lado, aumenta a espessura da folha nos perfilhos de idade mais avançada.

Pelo estudo de associação entre os índices de crescimento, observou-se maior correlação $(\mathrm{P}<0,05)$ da RAF com a $\operatorname{AFE}(r=0,95)$ do que com a $\operatorname{RPF}(r=0,21)$, o que indica efeito mais expressivo da AFE, que é componente morfológico e anatômico da RAF, no padrão de resposta da RAF do capim Coastcross-1. Desse modo, a redução na RAF com o incremento da idade de rebrotação do capim Coastcross-1 pode ser explicada, principalmente, pela redução na AFE (Tabela 3).
Independentemente da idade de rebrotação, houve efeito $(\mathrm{P}<0,05)$ da adubação nitrogenada em todos os índices de crescimento avaliados no primeiro e segundo cortes. Já no terceiro corte, somente para as variáveis área foliar por perfilho e índice de área foliar foram afetadas $(\mathrm{P}<0,05)$ pela dose de nitrogênio (Tabela 4).

No primeiro corte, a adubação nitrogenada não influenciou $(\mathrm{P}>0,05)$ a razão de área foliar, que apresentou valor médio de $11,1 \mathrm{~m}^{2} / \mathrm{kg}$. Porém, no segundo corte, esta variável aumentou $(\mathrm{P}<0,05)$ linearmente com a adubação nitrogenada, variando de 6,2 a $8,0 \mathrm{~m}^{2} / \mathrm{kg}$, nas doses de 0 a $133 \mathrm{~kg} /$ ha.corte, respectivamente (Tabela 4). A elevação da RAF com as doses de $\mathrm{N}$ ocorreu, principalmente, em função do acréscimo linear da AFE em resposta ao aumento das doses de $\mathrm{N}$ (Tabela 4), já que a AFE consiste em componente morfológico e anatômico da RAF. O incremento da AFE com a adubação nitrogenada pode ter ocorrido devido ao $\mathrm{N}$ aumentar as taxas de alongamento e aparecimento de folhas, resultando em folhas mais compridas e finas (Rovetta, 2000).

Conforme relatado, no presente trabalho, os menores valores de AFE foram observados na ausência de N. Valores inferiores de AFE também têm sido verificados em situações de déficit hídrico (Craufurd et al., 1999), onde também é comum a menor disponibilidade de $\mathrm{N}$ para a forrageira, tendo em vista que o $\mathrm{N}$ é transportado na matriz do solo até

Tabela 4 - Equações de regressão ajustadas aos valores dos índices de crescimento do capim Coastcross-1 em função das doses de nitrogênio $(\mathrm{N})$ no primeiro e segundo cortes

\begin{tabular}{|c|c|c|}
\hline Corte & Equação & $\mathrm{R}^{2}$ \\
\hline Primeiro & $\begin{array}{l}\text { Razão de área foliar }\left(\mathrm{m}^{2} / \mathrm{g}\right) \\
\hat{Y}=0,0111\end{array}$ & \\
\hline Segundo & $\begin{array}{l}\hat{Y}=0,0062261+0,0000138224 * * \mathrm{~N} \\
\text { Área foliar específica }\left(\mathrm{m}^{2} / \mathrm{g}\right)\end{array}$ & 0,94 \\
\hline Primeiro & $\hat{Y}=0,0168432+0,0000541698 * * * N$ & 0,52 \\
\hline Segundo & $\hat{Y}=0,011629+0,00004096 * * N$ & 0,92 \\
\hline $\begin{array}{l}\text { Primeiro } \\
\text { Segundo }\end{array}$ & $\begin{array}{c}\text { Razão de peso foliar }(\mathrm{g} / \mathrm{g}) \\
\hat{Y}=0,574707-0,00039418 * \mathrm{~N} \\
\hat{Y}=0,530648-0,000500127 * \mathrm{~N}\end{array}$ & $\begin{array}{l}0,81 \\
0,73\end{array}$ \\
\hline $\begin{array}{l}\text { Primeiro } \\
\text { Segundo }\end{array}$ & $\begin{aligned} & \text { Relação folha/colmo } \\
\hat{Y}= & 1,37981-0,00211485 * * N \\
\hat{Y}= & 1,15313-0,00232923 * N\end{aligned}$ & $\begin{array}{l}0,89 \\
0,80\end{array}$ \\
\hline $\begin{array}{l}\text { Primeiro } \\
\text { Segundo } \\
\text { Terceiro }\end{array}$ & $\begin{array}{l}\quad \text { Índice de área foliar } \\
\hat{Y}=1,01586+0,0185903 * \mathrm{~N} \\
\hat{Y}=1,66566+0,0162739 * \mathrm{~N} \\
\hat{Y}=1,35375+0,01747 * \mathrm{~N}\end{array}$ & $\begin{array}{l}0,83 \\
0,78 \\
0,82\end{array}$ \\
\hline $\begin{array}{l}\text { Primeiro } \\
\text { Segundo } \\
\text { Terceiro }\end{array}$ & $\begin{array}{l}\text { Área foliar por perfilho }\left(\mathrm{m}^{2}\right) \\
\hat{Y}=0,00135364+0,0000199629 * * \mathrm{~N} \\
\hat{Y}=0,00111238+0,000013312 * * \mathrm{~N} \\
\hat{Y}=0,00137254+0,0000201351 * * \mathrm{~N}\end{array}$ & $\begin{array}{l}0,94 \\
0,94 \\
0,92\end{array}$ \\
\hline
\end{tabular}

R. Bras. Zootec., v.40, n.10, p.2121-2128, 2011 
as raízes por fluxo de massa, processo dependente da adequada umidade no solo (Novaes \& Smith, 1999).

A razão de peso foliar (RPF) e a relação folha/colmo (RFC) decresceram $(\mathrm{P}<0,05)$ linearmente em função da dose de $\mathrm{N}$ no primeiro e segundo cortes (Tabela 4). Em gramíneas forrageiras, a redução da RPF com o aumento da dose de N indica a ocorrência de maior exportação de fotoassimilados das lâminas foliares para a síntese de tecidos em outros órgãos da planta, tal como o colmo, o que resulta na diminuição da sua RFC, conforme observado neste trabalho (Tabela 4).

No dossel forrageiro, o emprego de doses elevadas de $\mathrm{N}$ acelera o momento em que a competição intra-específica por luz ocorre, intensificando-a. Como uma das respostas à competição por luz é a elevação da taxa de alongamento do colmo (Lemaire, 2001), os perfilhos tornam-se maiores, com colmo mais desenvolvido e, por conseguinte, as plantas apresentam menor RPF e RFC. Adicionalmente, a maior disponibilidade de $\mathrm{N}$ faz com que os perfilhos passem mais rapidamente da fase vegetativa para a reprodutiva (Humphreys, 1979; Corsi, 1984), processo em que é inerente o maior desenvolvimento do colmo (Santos et al., 2009).

Uma das conseqüências da inferior RFC do capimcoastcross com a aplicação de $\mathrm{N}$ refere-se ao seu efeito sobre o valor nutritivo da forragem, que tende a ser comprometido, porque o colmo é de pior valor nutritivo do que a lâmina foliar (Santos et al., 2008).

Por outro lado, a adubação nitrogenada aumentou $(\mathrm{P}<0,05)$ linearmente o IAF do pasto, estimando-se valores de 1,0 e 3,5; 1,7 e 3,8; e 1,4 e 3,7 para o primeiro, segundo e terceiro cortes, nas doses de 0 e $133 \mathrm{~kg} / \mathrm{ha}$.corte de $\mathrm{N}$, respectivamente (Tabela 4). Rovetta (2000) também observou aumento no IAF do capim-tifton 85 até a dose de $133 \mathrm{~kg} /$ ha.corte de N. O incremento no IAF com a dose de N deve-se aos efeitos do $\mathrm{N}$ em elevar as taxas de aparecimento e alongamento foliar (Rovetta, 2000; Fagundes et al., 2006), gerando aumento $(\mathrm{P}<0,05)$ na área foliar por perfilho (Tabela 4).

Vale lembrar que o $\mathrm{N}$ não promoveu $(\mathrm{P}>0,05)$ alterações na densidade populacional de perfilho, característica estrutural importante e que também pode provocar mudanças no IAF do pasto (Chapman \& Lemaire, 1993). É provável que as maiores doses de $\mathrm{N}$ tenham resultado em maior taxa de crescimento do capim Coastcross-1, o que diminuiu a qualidade e intensidade da radiação na base das plantas, inibindo o perfilhamento (Langer, 1963). De outro modo, nos pastos não adubados com $\mathrm{N}$, a menor disponibilidade desse nutriente fez com que houvesse menor estímulo ao perfilhamento. Esses processos podem explicar a ausência de efeito da adubação nitrogenada sobre o número de perfilho por unidade de área no pasto de capim Coastcross- 1 .

No terceiro corte, a análise de variância revelou interação $(\mathrm{P}<0,05)$ entre dose de $\mathrm{N}$ e idade de rebrotação para as variáveis RAF, AFE, RPF e RFC (Tabelas 5 e 6). Dessa maneira, pelos resultados do desdobramento dessa interação, observou-se que, sob altas doses de $\mathrm{N}$ (100 e $133 \mathrm{~kg} /$ ha.corte), a RAF foi menor $(\mathrm{P}<0,05)$ na idade de 42 dias (Tabela 5). Estes resultados estão de acordo com os obtidos com outras gramíneas tropicais, em que demonstrou-se que a RAF decresce em plantas com idade mais avançada (Benincasa, 1988; Oliveira et al., 2000a; Gomide et al., 2003).

Entretanto, na ausência de N, os valores de RAF e AFE foram maiores aos 42 dias, em comparação com a idade de 28 dias (Tabela 5). Acredita-se que esse seja um mecanismo da forrageira de tolerância ao estresse nutricional, que faz com que a planta aumente sua área foliar e sua área foliar específica em situações de baixa disponibilidade de nutrientes para compensar a reduzida capacidade fotossintética de suas folhas na ausência de N (Liu \& Dickman, 1996). Esse padrão de resposta parece ter sido expresso, de maneira mais acentuada, na forrageira com 42 dias de rebrotação.

Tabela 5 - Valores médios dos índices de crescimento do capim Coastcross-1 sob doses de nitrogênio e colhido aos 28 e 42 dias de rebrotação, no terceiro corte

\begin{tabular}{|c|c|c|}
\hline \multirow{2}{*}{$\begin{array}{l}\text { Dose de nitrogênio } \\
\text { (kg/ha.corte de } \mathrm{N})\end{array}$} & \multicolumn{2}{|c|}{ Idade de rebrotação } \\
\hline & 28 dias & 42 dias \\
\hline & \multicolumn{2}{|c|}{ Razão de área foliar $\left(\mathrm{m}^{2} / \mathrm{kg}\right)$} \\
\hline 0 & $5,7 \mathrm{~b}$ & $7,7 a$ \\
\hline 33 & $7,6 a$ & $7,8 \mathrm{a}$ \\
\hline 66 & $8,9 a$ & $8,5 a$ \\
\hline 100 & $10,2 \mathrm{a}$ & $8,8 b$ \\
\hline \multirow[t]{2}{*}{133} & $10,0 \mathrm{a}$ & $8,6 b$ \\
\hline & \multicolumn{2}{|c|}{ Área foliar específica $\left(\mathrm{m}^{2} / \mathrm{kg}\right)$} \\
\hline 0 & $8,6 b$ & $14,3 a$ \\
\hline 33 & $13,7 a$ & $15,6 a$ \\
\hline 66 & $16,9 a$ & $17,3 \mathrm{a}$ \\
\hline 100 & $20,0 \mathrm{a}$ & $17,3 \mathrm{~b}$ \\
\hline \multirow[t]{2}{*}{133} & $18,6 a$ & $17,8 \mathrm{a}$ \\
\hline & \multicolumn{2}{|c|}{ Razão de peso foliar (g/g) } \\
\hline 0 & $0,6632 \mathrm{a}$ & $0,5390 b$ \\
\hline 33 & $0,5503 a$ & $0,5010 \mathrm{~b}$ \\
\hline 66 & $0,5273 a$ & $0,4913 a$ \\
\hline 100 & $0,5141 \mathrm{a}$ & $0,5059 a$ \\
\hline \multirow[t]{2}{*}{133} & $0,5401 \mathrm{a}$ & $0,4842 b$ \\
\hline & \multicolumn{2}{|c|}{ Relação folha/colmo } \\
\hline 0 & $1,89 \mathrm{a}$ & $1,17 \mathrm{~b}$ \\
\hline 33 & $1,23 \mathrm{a}$ & $1,00 \mathrm{~b}$ \\
\hline 66 & $1,14 \mathrm{a}$ & $0,97 a$ \\
\hline 100 & $1,06 a$ & $1,01 \mathrm{a}$ \\
\hline 133 & $1,18 \mathrm{a}$ & $0,94 b$ \\
\hline
\end{tabular}

Médias seguidas por letras iguais na mesma linha não diferem pelo teste $\mathrm{F}$ $(\mathrm{P}>0,05)$. 
Deve-se considerar que alterações nos índices de crescimento são bastante complexas e difíceis de serem interpretadas, principalmente em situações de campo, onde os fatores de ambiente (água, luz, temperatura, nutrientes e outros) podem interagir e determinar mudanças morfofisiológicas na planta.

De maneira geral, a razão de peso foliar (RPF) e a relação folha/colmo (RFC) reduziram com a maturidade do capim Coastcross-1, sendo observados maiores valores aos 28 dias, diferindo significativamente $(\mathrm{P}<0,05)$ nas doses de 0 , 33 e $133 \mathrm{~kg} /$ ha.corte de N (Tabela 5). A redução na RPF com o aumento da idade de rebrotação pode ser atribuída à diminuição na RFC do capim Coastcross-1 nesse período, conforme já explicado.

Os maiores valores de RPF e RFC nas idades de 28 e 42 dias foram observadas na ausência de N. Se considerarmos que o contínuo incremento na produção de forragem está associado à crescente participação de colmo na biomassa do pasto (Oliveira et al., 2000b), qualquer fator que limite o crescimento da forrageira, como a falta de $\mathrm{N}$, associada aos cortes mais freqüentes (28 dias), prejudica também o alongamento de colmo, resultando em altos valores de RFC e de RPF (Tabela 5).

No que tange às respostas dos índices de crescimento do capim Coastcross-1 no terceiro corte em função da aplicação de N (Tabela 6), constatou-se efeito mais expressivo aos 28 dias de rebrotação. Isso pode ser verificado quando se comparam os coeficientes angulares das equações de regressão nas duas idades de rebrotação, cujos valores sempre foram superiores na idade de 28 dias.

Aos 28 dias de rebrotação, estimaram-se valores de RAF de 6,2 e $11,0 \mathrm{~m}^{2} / \mathrm{kg}$, respectivamente, para as doses de

Tabela 6 - Equações de regressão ajustadas aos valores dos índices de crescimento do capim Coastcross-1 colhido aos 28 e 42 dias de rebrotação, no terceiro corte, em função das doses de nitrogênio $(\mathrm{N})$

\begin{tabular}{|c|c|c|}
\hline $\begin{array}{l}\text { Idade de } \\
\text { rebrotação (dia) }\end{array}$ & Equação & $\mathrm{r}^{2}$ \\
\hline & Razão de área foliar $\left(\mathrm{m}^{2} / \mathrm{g}\right)$ & \\
\hline 28 & $\hat{Y}=0,006227+0,000033946 * * N$ & 0,90 \\
\hline 42 & $\hat{Y}=0,0077174+0,000008504 * N$ & 0,81 \\
\hline & Área foliar específica $\left(\mathrm{m}^{2} / \mathrm{g}\right)$ & \\
\hline 28 & $\hat{Y}=0,010324+0,0000787437 * N$ & 0,83 \\
\hline 42 & $\hat{Y}=0,014732+0,000026174 * * N$ & 0,87 \\
\hline & Razão de peso foliar (g/g) & \\
\hline 28 & $\hat{Y}=0,615197-0,00084595 * * * N$ & 0,55 \\
\hline 42 & $\hat{\mathrm{Y}}=0,5251-0,00031336 * * * \mathrm{~N}$ & 0,61 \\
\hline & Relação folha/colmo & \\
\hline 28 & $\hat{\mathrm{Y}}=1,616-0,00474028 * * * \mathrm{~N}$ & 0,56 \\
\hline 42 & $\hat{Y}=1,1116-0,001394 * N$ & 0,64 \\
\hline
\end{tabular}

$*, * *, * * *$ Significativo ao nível de 5,1 e $10 \%$ de probabilidade, respectivamente, pelo teste F.
0 e $133 \mathrm{~kg} /$ ha.corte de $\mathrm{N}$, enquanto, aos 42 dias, estimaram-se valores de 7,0 a $8,8 \mathrm{~m}^{2} / \mathrm{kg}$ para as mesmas doses de $\mathrm{N}$. O efeito mais pronunciado do $\mathrm{N}$ em aumentar a área foliar útil para fotossíntese, definida como a RAF (Benincasa, 1988), aos 28 dias de rebrotação, provavelmente deve-se à maior demanda de $\mathrm{N}$ para a produção de folhas na fase inicial de desenvolvimento da gramínea. Já em idades mais avançadas, o N pode ser mobilizado para a síntese de outros órgãos, tal como colmo e inflorescência, fazendo com que seu efeito em aumentar a RAF seja menor.

$\mathrm{O}$ incremento da RAF em função da dose de $\mathrm{N}$ foi determinado, em parte, pelo aumento da AFE do capim Coastcross- 1 com a adubação nitrogenada (Tabela 6). Esse argumento é válido, se considerarmos que a AFE constitui componente morfológico e anatômico da RAF (Benincasa, 1998). O aumento nos valores de RAF e AFE com o incremento da doses de $\mathrm{N}$ também foi observado por Rovetta (2000), em estudo com o capim-tifton 85. Conforme mencionado anteriormente, $\mathrm{o} \mathrm{N}$ pode resultar na formação de lâminas foliares mais compridas, porém menos espessas (Rovetta, 2000).

Por outro lado, a adubação com $\mathrm{N}$ provocou redução acentuada na relação folha/colmo (RFC) do capim coastcross-1, principalmente aos 28 dias de rebrotação. De fato, o coeficiente angular da equação ajustada aos dados de RFC na idade de 28 dias foi aproximadamente 3,4 vezes mais negativo ao da equação ajustada na idade de 42 dias (Tabela 6). É provável que, na maior idade de rebrotação (42 dias), o estádio de desenvolvimento mais avançado do capim Coastcross- 1 foi preponderante em diminuir sua RFC, o que impediu que o efeito do $\mathrm{N}$ se expressasse de modo mais proeminente.

Diante do exposto, para evitar redução na RFC e seus efeitos desfavoráveis na qualidade e estrutura do pasto, bem como na eficiência de pastejo, deve-se evitar a aplicação de altas doses de $\mathrm{N}$ em pastagens, cujo manejo da desfolhação não será ajustado e, ou, alterado. Em verdade, como regra geral, a frequência de desfolhação em pastos adubados deve ser maior, independentemente do sistema de pastejo e do critério de manejo adotado, a fim de que se obtenha maior eficiência com a adubação (Fonseca et al., 2008). Alvim et al. (1996), trabalhando com o capim Coastcross- 1 submetido a quatro doses de $\mathrm{N}(0,250,500 \mathrm{e}$ 750 kg/ha.ano), também verificaram tendência de redução na RFC com o aumento da dose deste nutriente na época das chuvas, enquanto que na época da seca, verificou-se o aumento na RFC de 0,9 a 1,1.

Os resultados apresentados nesse trabalho demonstram que o padrão de acúmulo de forragem do capim Coastcross-1 é alterado pela aplicação de distintas doses de nitrogênio no 
pasto (Tabelas 4, 5 e 6). Sendo assim, em pastagens adubadas com níveis particulares de fertilizante nitrogenado, os processos determinantes do acúmulo de foragem, como taxas de crescimento de folha e de colmo, são diferentes (Tabelas 5 e 6), o que exige a adoção de ações de manejo da desfolhação também diferenciadas.

Em verdade, pela análise das variáveis respostas que responderam de forma interativa às doses de $\mathrm{N}$ e às idades de rebrotação (Tabelas 5 e 6), infere-se que, nos meses de primavera e verão, pastos de capim Coastcross-1 adubados com maiores doses de $\mathrm{N}$ devem ser manejados com menor idade de rebrotação (28 dias), isto é, com período de descanso menor ou frequência de desfolhação alta. Contrariamente, o pasto de capim Coastcross-1 com ausência de adubação nitrogenada, ou adubado com dose pequena de $\mathrm{N}$, pode ser manejado com maior idade de rebrotação (maior período de descanso). Essas recomendações de manejo visam melhorar as características estruturais do pasto, de modo que os mesmos tenham maior participação de folhas em detrimento ao colmo e, com efeito, sejam de melhor valor nutritivo e predisponente ao consumo e desempenho animal.

\section{Conclusões}

A idade de rebrotação e a adubação nitrogenada modificam o padrão de acúmulo de forragem e as características do pasto de capim Coastcross-1. Durante a estação de maior crescimento, o pasto de capim Coastcross-1 adubado com maior dose de nitrogênio deve ser manejado com menor idade de rebrotação (28 dias), enquanto que aquele não adubado, ou adubado com dose pequena de nitrogênio, pode ser manejado com maior idade de rebrotação (42 dias).

\section{Referências}

ALVIM, M.J.; RESENDE, H.; BOTREL, M.A. Efeito da frequência de cortes e do nível de nitrogênio sobre a produção e qualidade da matéria seca do "coast-cross". In: WORKSHOP SOBRE O POTENCIAL FORRAGEIRO DO GÊNERO CYNODON, 1996, Juiz de Fora. Anais... Juiz de Fora: EMBRAPA-CNPGL, 1996. 181p.

BENINCASA, M.M.P. Análise de crescimento de plantas: noções básicas. Jaboticabal: FUNEP, 1988. 41p.

CHAPMAN, D.F.; LEMAIRE, G. Morphogenetic and structural determinants of plant regrowth after defoliation. In: INTERNATIONAL GRASSLAND CONGRESS, 17., 1993, New Zealand. Proceedings... New Zealand: s. ed., 1993. p.95-104.

CORSI, M. Effects of nitrogen rates and harvesting intervals on dry matter production, tillering and quality of the tropical grass Panicum maximum Jacq. 1984. 125f. Thesis (Ph.D. in Agronomy) - Ohio State University, Wooster.

CRAUFURD, P.Q.; WHEELER, T.R.; ELLIS, R.H. et al. Effect of temperature and water deficit on water-use efficiency, carbon isotope discrimination, and specific leaf area in peanut. Crop Science, v.39, p.136-142, 1999.
EUCLYDES, R.F. Sistema para análises estatísticas - SAEG. v.5.0. Viçosa, MG: Funarbe, UFV, 1993.

FAGUNDES, J.L.; FONSECA, D.M.; MISTURA, C. et al Características morfogênicas e estruturais do capim-braquiária em pastagem adubada com nitrogênio avaliadas nas quatro estações do ano. Revista Brasileira de Zootecnia, v.35, n.1, p.21-29, 2006.

FONSECA, D.M.; SANTOS, M.E.R.; MARTUSCELLO, J.A. Adubação de pastagens no Brasil: uma análise crítica. In: SIMPÓSIO SOBRE MANEJO ESTRATÉGICO DA PASTAGEM, 4., 2008,Viçosa, MG Anais... Viçosa, MG: UFV, 2008. p.295-334.

GASTAL, F.; NELSON, C.J. Nitrogen use within the growing leaf blade of tall fescue. Plant Physiology, v.105, p.191-197, 1994.

GOMIDE, C.A.M.; GOMIDE, J.A.; ALEXANDRINO, E. Índices morfogênicos e de crescimento durante o estabelecimento e a rebrotação do capim-mombaça (Panicum maximum Jacq.). Revista Brasileira de Zootecnia, v.32, n.3, p.795-803, 2003.

GOMIDE, C.C.C. Algumas características fisiológicas e químicas de cinco cultivares de Cynodon. 1996. 100f. Dissertação (Mestrado em Zootecnia) - Faculdade de Ciências Agrárias e Veterinárias, Universidade Estadual Paulista, Jaboticabal.

LAMBERS, H. Does variation in photosynthesis rate explain variation in growth rate and yield? Netherlands Journal Agricultural Science, v.35, n.4, p.505-519, 1987.

LANGER, R.H.M. Tillering in herbage grass. A review. Herbage Abstracts. v.33, p.141-148, 1963.

LEMAIRE, G. Ecophysiology of grasslands: dynamic aspects of forage plant populations in grazed swards. In: INTERNATIONAL GRASSLAND CONGRESS, 19., 2001, São Pedro, 2001. Proceedings... São Pedro: FEALQ, 2001. p.29-37.

LIU, Z.; DICKMANN, D.I. Effects of water and nitrogen interaction on net photosynthesis, stomatal conductance, and water-use efficiency in two hybrid poplar clones. Plant Physiology, v.97, p.507-512, 1996.

MacADAM, J.W.; VOLENEC, J.J.; NELSON, C.J. Effects to nitrogen on mesophyll cell division and epidermal cell elongation in tall fescue leaf blades. Plant Physiology, v.89, p.549-556, 1989.

McMAHOM, C. Size and shape in biology. Science, v.179, p.1201-1204, 1973.

OLIVEIRA, M.A.; PEREIRA, O.G.; GARCIA, R. et al. Rendimento e valor nutritivo do capim-tifton 85 (Cynodon spp.) em diferentes idades de rebrota. Revista Brasileira de Zootecnia, v.29, n.6, p.1949-1960. 2000b (supl. 1).

OLIVEIRA, M.A.; PEREIRA, O.G.; GOMIDE, J.A. et al. Análise de crescimento do capim-bermuda 'Tifton 85' (Cynodon spp.). Revista Brasileira de Zootecnia, v.29, n.6, p.1930-1938. 2000a (Supl. 1).

RADFORD, P.J. Growth analysis formulae. Their use and abuse. Crop Science, v.7, n.3, p.171-175, 1967.

ROVETTA, R. Morfogênese e análise de crescimento do capim-tifton 85 (Cynodon spp.), sob diferentes dose de nitrogênio, colhido ao atingir 30,40 e $50 \mathrm{~cm}$ de altura. 2000. 56f. Dissertação (Mestrado em Zootecnia) - Universidade Federal de Viçosa, Viçosa, MG.

SANTOS, M.E.R.; FONSECA, D.M.; BALBINO, E.M. et al. Caracterização de perfilhos em pastos de capim-braquiária diferidos e adubados com nitrogênio. Revista Brasileira de Zootecnia, v.38, n.4, p.643-649, 2009.

SANTOS, M.E.R.; FONSECA, D.M.; EUCLIDES, V.P.B. et al. Valor nutritivo da forragem e de seus componentes morfológicos em pastagens de Brachiaria decumbens diferida. Boletim da Indústria Animal, v.65, n.4, p.303-311, 2008.

TAIZ, L.; ZEIGER, E. Fisiologia vegetal. 3.ed. Porto Alegre: Artmed, 2006. 719p.

VILELA, D.; PAIVA, P.C.A.; LIMA, J.A. et al. Morfogênese e acúmulo de forragem em pastagem de Cynodon dactylon cv. coastcross em diferentes estações de crescimento. Revista Brasileira de Zootecnia, v.34, n.6, p.1891-1896, 2005.

WATSON, D.J. The physiological basis of variation in yield Advances in Agronomy, v.4, p.101-145, 1952. 